\title{
All Sciences Are Human and No Science Is Exact
}

\author{
Agamenon R. E. Oliveira \\ Department of Structures, Polytechnic School of UFRJ, Rio de Janeiro, Brazil \\ Email: agamenon.oliveira@globo.com
}

How to cite this paper: Oliveira, A. R. E. (2020). All Sciences Are Human and No Science Is Exact. Advances in Historical Studies, 9, 113-122. https://doi.org/10.4236/ahs.2020.93010

Received: May 21, 2020

Accepted: September 14, 2020

Published: September 17, 2020

Copyright $\odot 2020$ by author(s) and Scientific Research Publishing Inc. This work is licensed under the Creative Commons Attribution International License (CC BY 4.0).

http://creativecommons.org/licenses/by/4.0/

\begin{abstract}
The vertiginous development of science in the last decade, in several different fields such as nanoscience, neurosciences, artificial intelligence, and the promise of the quantum computer in the near future, requires constant reflection from scientists, philosophers, and epistemologists about the profound implications of this in these different fields of knowledge and for society. This paper aims to raise some ideas that can help in this reflection and show that all scientific areas are interconnected, implying that the results obtained in the technological areas depend on other sciences and even on philosophy by the very nature of scientific knowledge. Furthermore, the established separation of disciplines, which is made by universities, placing human sciences on one side and exact sciences on the other, is questionable and insufficient to account for the complexity in the classification of sciences. It needs further epistemological deepening.
\end{abstract}

\section{Keywords}

Epistemology and Philosophy, Classification of Sciences, History of Sciences

\section{Introduction}

First, it is necessary to recognize that it is not an easy task to classify the entire field of scientific knowledge. Evidently, any classification of the sciences must necessarily contemplate their development (Lefebvre, 2002), the processes of unification of different fields, and the emergence of new ones, as well as to correctly fitting in areas that are in the interfaces and that raise doubt about their best positioning.

The first system for the classification of the sciences was proposed by Aristotle (384 BC-322 BC). He divided them into three different types: productive sciences, concerned with some type of manufacturing; practical sciences, which used knowledge for action or some purpose or utility; and theoretical sciences, which sought knowledge through knowledge, regardless of any purpose or utility. This classi- 
fication remained until the 17th century, when the Scientific Revolution caused the separation of knowledge into the philosophical, scientific, and technical areas. The current classification mainly considers and prioritizes the problem of the separation between the subject (cognitive) and object (knowledge). The latter, in the so-called exact sciences such as physics, chemistry and biology, keeps a distance from the subject to the point that in the process of knowledge, that is, in the interaction between subject and object, "true" knowledge of the object is possible without any contamination during this interaction. The current classification system of scientific knowledge is subdivided as follows (Popper, 1959):

- Mathematical or logical-mathematical sciences: arithmetic, geometry, logic, pure physics, etc.

- Natural sciences: physics, chemistry, biology, geology, astronomy, etc.

- Human or social sciences: psychology, sociology, anthropology, economics, linguistics, history, etc.

- Applied sciences: Engineering sciences, medicine, architecture, computer sciences, etc.

The basis of the classification is problematic precisely when the subject's actions start to interfere in the desired result, which is the case of the humanities (Oliveira, 2013). This form of classification also presents a greater problem when we look at scientific development from a historical point of view greatly weakening the classification of the sciences in the field of the so-called "exact sciences", denouncing accuracy as a completely inappropriate term. In this paper, we will try to present some critical arguments to the current classification and to point to other possibilities for classification criteria. We will also show that the results in the technological field are dependent on the scientific development of the humanities and philosophy.

\section{All Sciences Are Human}

All sciences, located in any field, are forms of knowledge that have developed historically, so that all scientific theories are logical constructions that seek to establish through their laws or principles, a form and a rule of relationship between their parts. In the so-called inductive sciences, laws or forms of internal regularity come from empirical evidence obtained through the senses and organized into a theory, which seeks to frame all phenomena through a deduction process contained in those same laws or principles (Popper, 1972).

It is essential to add that these laws or principles have to be validated by experiments that prove them, as well as by their universality. For example, in Mechanics, the science of movement, when the order of magnitude of the speed of the objects is far from the speed of light it is part of classical mechanics, as it falls in the problems studied by the three laws of Newton (1642-1727). To reach its current stage this theory developed over almost two thousand years. Only in 1687, with the publication of Newton's Principia, was it possible to reach this level of maturity to the point of becoming a true theory. Thus, even physics, 
which studies movement and other natural phenomena, is a historical and, therefore, human construction. In this sense, when compared with the human sciences in the current classification from this historical point of view, they do not differ in terms of their development. The difference lies in the question of the separation between the subject and the object because in the human sciences this separation is difficult and in some cases impossible.

\section{Why Is No Science Exact?}

Since scientific development is historical, every scientific theory has a provisional dimension and, in principle, can be altered or even completely replaced by another, whenever a new phenomenon that does not fit into the body of the theory puts the older one in check. This means that human beings were also building throughout history new instruments and forms of knowledge that could improve or replace theories that do not respond to the challenge posed by new phenomena. It, therefore, does not make much sense to speak of the accuracy of knowledge that is provisional and can be reformulated or even refuted. The new theories of physics that emerged at the beginning of the 20th century confirm what we say. The discovery that the speed of light is constant and acts as a ceiling which can reach a body, forced physicists to reformulate classical mechanics and to construct the theory of relativity (Mosley \& Linch, 2010).

Looking in the opposite direction, talking about exact sciences means that theories in the field of knowledge have reached a definitive stage and can never be changed again. If this were to happen knowledge would deny itself and reach a status of dogma, that is, absolute truth, in no case questionable and placed on a pedestal of contradictory and petrified perfection.

Fortunately, this does not happen. The process of knowledge is dynamic, vulnerable to criticism and questioning, including what is more radical, and can be replaced by another more appropriate, more powerful, interpretation and explanation.

\section{Bachelard's Approximate Knowledge}

In his famous Essay on approximate knowledge, published initially in 1928, Gaston Bachelard (1884-1962) takes a very clear epistemological position regarding the approximate nature of scientific knowledge (Bachelard, 2004). He defines scientific knowledge as that which resists the subject and, consequently, suggests that it can be adopted, as a postulate of epistemology, in other words, its unfinished character. Thus, the act of knowing is never complete, error being something that cannot be totally eliminated. Since error is inherent in the knowledge process, we are thus forced to work with approximations, even in the so-called exact sciences.

In his aforementioned essay, Bachelard shows first of all the role of approximate knowledge in the experimental sciences, in which, according to him, the process is necessarily finite. Since it is necessarily based on a system of measures, this field makes knowledge of error a central issue and starting point. He then 
turns to the mathematical sciences in which the approach seems subject to progressive rules, susceptible to infinite development.

In the final part of the work, according to the criteria he established, the problem of truth is addressed. Bachelard then postulates a philosophy of the inaccurate which can bring a new meaning to the traditional concepts of reality and truth.

Bachelard influenced a host of eminent thinkers, both in France and in other countries. Among the French thinkers, we can cite Georges Canguilhem (1904-1995), Gilbert Simondon (1924-1989), Roland Barthes (1915-1980), Michel Foucault (1926-1984), Bruno Latour (1947), and Pierre Bourdieu (1930-2002), among many others.

\section{Feyerabend's Theory of Error}

In his thought-provoking 1975 essay Against the Method, in which he proposes an anarchist theory of knowledge, Paul Karl Feyerabend (1924-1994) develops a theory of error. He claims that science, as we find it, is a combination of certain rules and error. It is thus necessary for the scientist who works in a given particular situation to learn to recognize error and to live with it, also bearing in mind that he is subject to incorporating new errors.

Scientists need a theory of error instead of looking for infallible rules that lead to an approximation of the truth. Error itself, according to Feyerabend, is a historical phenomenon. As he states: A theory of error should contain rules based on experimental and practice, useful indications, heuristic suggestions rather than general laws, and these indications and suggestions must be related to historical episodes in order to see in detail how some of them have led to success on certain occasions (Feyerabend, 1987).

Later, he concludes: After all, the History of Sciences not only consists of facts and conclusions drawn from them. It is also composed of ideas, interpretations of facts, problems created by the conflict of interpretation, the action of scientists... Therefore, the History of Sciences will be as complex, as chaotic, as full of errors and fun as are the minds of those who invented them (Feyerabend, 1987).

At the end of his famous essay, Feyerabend again criticizes the idea of a science that can be governed or regulated by a set of fixed rules and whose rationality consists of being in accordance with those rules. He sees this view as being unrealistic and flawed, which implies accepting error and imperfections within scientific knowledge.

\section{Not Even Mathematics Is an Exact Science}

Until the beginning of the 20th century, the dream of the great mathematicians and logicians, especially Hilbert (1862-1943), was to discover a set of logical principles to the point of deducing all the mathematical knowledge from these principles. Basically, he was trying to generalize what had happened to Euclid's (330 BC-?) geometry. His Elements, a work published around 300 BC, placed 
geometry at the highest scientific level by establishing a set of principles from which its geometry derived. In the 19th century, a Russian mathematician named Lobachevski (1792-1856), while trying to prove the postulate of Euclid's parallels, the so-called fifth postulate, created a new so-called non-Euclidian geometry, from which later it was later found that the distance between two points is no longer a straight line. The sum of the internal angles of a triangle can be greater or smaller than two right angles.

In 1931, the Austrian logician named Kurt Gödel (1906-1978) demonstrated a theorem called the incompleteness theorem (Gödel, 1989). He proved that in an axiomatic system, if it obeys the arithmetic logic, even if it is consistent, it is still incomplete, in other words, there is at least one truth that needs to be proved outside it. This overturned the dream of many famous mathematicians and proved that mathematics, considered as an exact science, actually had elements of incompleteness in its system and in some cases could not even prove its consistency (Dowek, 2007).

\section{The Church Theorem}

The solution to the problem of decidability was presented independently in 1936 by Alonso Church (1903-1995) and Alan Turing (1912-1954). What was found from these results was that there is no decision algorithm for the logical predicates, therefore, there is a difference in nature between reasoning and calculation and Hilbert's program of replacing reasoning with calculation was a failure.

In the middle of the twentieth century it was concluded that reasoning should become an object of study itself. It was thus necessary to explicitly define the rules of deduction and the grammar of the propositions used in the reasoning. Similar to presenting their solution to the decision problem, Church and Turing made calculation an object of study in itself. Both showed that there is no algorithm to solve a certain type of problem, requiring an explicit definition of the notion of algorithm and calculable function (Dowek, 2007).

A demonstration of the physical form of Church's thesis was presented by Robin Gaudy (1919-1995) in 1978. This demonstration initially assumes that physical space is an ordinary three-dimensional geometric space. After this two hypotheses were formed about its physical nature: 1) the finitude of the information density; 2) the finitude of the transmission speed of information. The first hypothesis means that a physical system of finite dimension can only be constituted by states with a finite number of different states. The second hypothesis that the state of one system cannot influence the state of another system until after a delay in time, proportional to the distance between the two states.

Although, it is not our goal to develop this theme in the present paper. Church's theorem in its physical form sheds new light on a question of an old epistemological nature that dates back to Kepler (1571-1630) and Galileo (1564-1642), namely the adequacy of mathematics to describe physical phenomena and the great success of mathematical physics. 


\section{Anthropological Unification of Sciences}

Natural sciences are deeply related to human sciences because man cannot develop an understanding of nature in a pure form outside society, but rather is integrated in the human world by means of labor. This implies that our knowledge of nature is anthropological knowledge (Marx \& Engels, 1968).

For Marx (1818-1883) natural sciences are human sciences and the sense of his analysis is that man is the immediate object of natural sciences and nature is the immediate object of man. While natural sciences are sciences of man, the latter are natural sciences. Thus, to Marx there is an inseparable unity between these two fields of knowledge. Marx foresees for the future a fusion between the two fields because of the common anthropological basis.

Marx also looks at the division between man and nature that implies a division between the natural sciences and human sciences as being due to an alienated relationship. This concept is related to the separation between man and the products of his labor. These ideas are presented and developed in Marx's texts about the relationship between man and nature and we will use this framework for our future analysis.

An example of an inextricable relationship between natural and human sciences is the evolution of the scientific-natural model of objectivity. Natural sciences acquired a progressive freedom from ideological and value judgments over a very long historical process. During feudalism the weakness of the dominant classes from a political and military point of view led to increased fighting of enemies in the ideological field to maintain the system of domination. The ideological system of established values was composed of dogmas and in complete agreement with the static and immutable order of the universe. Hence, it is easy to understand why any controversy or divergences with that order even through the natural sciences was punished with rigor and violence as heretic manifestations. Thus, the examples of Giordano Bruno (1548-1600) and Galileo Galilei (1564-1642) illustrate this situation. The political and ideological struggle occurred in the natural sciences field.

With the birth and development of the capitalist mode of production discussions of the natural sciences lost their ideological nature. This happened because capital in general and especially after the Industrial Revolution needed scientific knowledge, while ideological conflicts disputes were displaced towards social and economic questions where the appropriation of the products generated by labor occurred. As soon as the capitalist mode of production was established in most cities in Europe, at the end of eighteenth and beginning of the nineteenth centuries, the natural sciences were emancipated and dissociated from a religious ideological basis. It is no coincidence that this period was characterized by the preeminence of Enlightenment philosophers who directed their critiques against religious feudalism, authority principle, and scholastic dogmatism in a fundamental step to the transformation of the scientific-natural model of objectivity. 
Later, this model matured and a new epistemological ideal based on a science free from ideology and value judgments appeared as a kind of neutral science. This ideal in extreme situations created the positivist scientific model.

Nowadays ideological questions remain in the natural sciences in a transformed way. The selection of research themes, technical applications, and their discovery depends on economic and social group interests that have control of investments and appropriation of gains.

If we analyze the model of scientificity where fields of knowledge are separated, a comparison between the natural sciences and human sciences can show that there is no absolute difference between them. In addition, shadow areas exist, fields of transition and interfaces between both types of science. In these cases, we can find ecology, some parts of biology, comparative psychology, etc. Both natural and human knowledge are required for this.

With respect to the human and social sciences, unlike Auguste Comte (17981857) and the positivist school it is impossible to separate scientific knowledge from value judgments. Michel Löwy (1938) uses a physical metaphor to characterize this problem (Löwy, 1987). He said that when a natural science approaches the border which separates it from human sciences there is a kind of "ideological heating" and it becomes electrically charged.

Despite this epistemological impossibility, positivists persisted with their analysis and their model of objectivity. They denied the difference between the two fields and postulate a similarity between the natural and social laws.

\section{Difficult to Classify Sciences}

Some sciences, such as ecology, find it very difficult to be classified by the model that privileges the object of knowledge (Hughes, 2001). This is for a very simple reason. Their object of knowledge is found both in the field of exact sciences, such as physics, chemistry and biology, as well as being deeply immersed in the sciences of society. In addition, human action on the environment, and consequently in society, also triggers the modifications of man on his own. Relations between subject and object are constantly changing in a more complex system of causal relations. Thus, ecology, it can be said, belongs to the two epistemological fields, in other words, the exact sciences and the human sciences.

Another example comes from economic science itself, considered a social and therefore human science. For many years, this science has received contributions from the field of exact sciences as is the case of physics. In his studies, the Romanian economist and mathematician Georgescu Roengen (1906-1994) expanded his object of knowledge and his spectrum of analysis, for example by introducing the second law of thermodynamics into economics (Hall \& Klitgaart, 2018).

There are other examples of change, or better of expanding the epistemological field as is the case of psychoanalysis, considered by many philosophers and historians of science as a non-science, because it is based on knowledge that, according to them, lacks experimental proof. Recently, with the great development of neuroscience, many of the proposals and analysis schemes used by Freud 
(1856-1939), have been proven in the laboratory. This only proves that the classification systems of science must be constantly reassessed and adapted to new scientific developments.

\section{Applied Knowledge Depends on Other Sciences}

Often, governments with a liberal profile have threatened to make budget cuts in the areas of the social sciences and philosophy, as a way of obtaining more immediate results from scientific progress for their countries. However, if the government policy of discouraging the teaching of social sciences and philosophy is successful, the results soon will be felt in the scientific production of the country as a whole, including the applied sciences and technology. This is because it will soon lead to a drop in the quality of education at all levels and, consequently, in the university itself, which will start to admit less prepared students and with increasing quality deficiencies in their training. In addition, scientific and technological production in all areas is increasingly interdisciplinary: work teams are composed of people with different backgrounds, including those from the humanities, such as economists, sociologists at work, specialists in labor management of knowledge, HR professionals and administrators focused in training, among others. The loss of this diversity will lead to decreased productivity, the impoverishment of work, bringing huge losses to the country, since if sectors become less productive they will become more vulnerable to international competition and deindustrialization.

Finally, there is the issue of scientific training being supported by critical thinking. Science itself is critical thinking par excellence. According to the philosopher of science Karl Popper (1902-1994), scientific theories are constructed through conjectures and refutations, the title of one of his most famous books (Popper, 1972). In this sense, the profession of scientist is perhaps the only one that differs significantly from all others. By the very nature of their work, scientists constantly explain and correct their errors, elaborating new more consistent conjectures and, again, subjecting them to the sieve of reality.

In another sense, weakening the humanities and philosophy affects the formation of citizenship, since it is through the knowledge coming from these areas, together with the most specific disciplines of each career, that we form conscious and enthusiastic citizens, critical, and capable of fighting for liberties and democracy in the country. So, relegating the social sciences and philosophy to a lower level by teaching other subjects is part of an authoritarian project, eager for the weakening of citizenship and to subject society to political manipulation.

\section{Final Remarks and Conclusion}

In this short paper, in a very succinct way, we try to problematize the current classification of sciences in the light of their own recent development, directing our criticism to the classification criteria based on the separation between subject and object. Also shown is the inaccurate and approximate character of scientific knowledge even in mathematics, with contributions from Church's theorem 
and Turing's studies. Still in the classificatory field, it was shown that certain scientific areas are difficult to find and adequate classification hard because often their objects are often confused with the subject, creating difficulties in its allocation to a certain field.

To enrich the epistemological debate, we believe that it is necessary to contribute ideas that replace the extreme fragmentation of the object of knowledge and reintegrate the relationship between the subject and the object, examining differently the relationships between the parts and the whole in a given system, contemplating their specificities. We also believe that the problems posed by the theory of complexity are pertinent and can be very useful for the analysis of sciences such as nanoscience, neurosciences and environmental sciences, and can result in novel insights for a new discussion of the classification of sciences. In this sense, the epistemologies of Edgar Morin (1921), Enrique Leff (1946), and Humberto Maturana (1928) certainly make enormous contributions to a new look at the sciences. With respect to complexity theory, the current development of sciences points to a paradigm shift, provisionally called the post-Newtonian paradigm, for the lack of a better name. If this happens, it will consist of incorporating new theoretical structures into sciences, expanding the concepts from systems theory that have been greatly enriched by recent developments in computer and information sciences. In addition, three more areas of scientific knowledge should play an important role: 1) the theory of non-linear systems and chaos theory; 2) network theory; 3) the theory of adaptative systems and their self-organization.

Finally, the interconnection between scientific disciplines and the humanities establishes a network of interdependence where a disturbance at a given point can significantly change other parts of the system. It is the case that we try to show where a decrease in funding in the humanities and philosophy can alter and cause serious damage to the technological area. A deepening of these issues is beyond the scope of this paper, but it is increasingly necessary in view of the enormous progress of sciences and technology, especially in relation to science and technology today. However, we believe that this project will be a collective work and not only a task for epistemologists.

\section{Conflicts of Interest}

The author declares no conflicts of interest regarding the publication of this paper.

\section{References}

Bachelard, G. (2004). Essay on Approximate Knowledge. Rio de Janeiro: Editora Contraponto.

Dowek, G. (2007). The Metamorphoses of Calculus. Paris: Le Pommier.

Feyerabend, P. K. (1987). Contra el método. Barcelona: Editorial Ariel.

Gödel, K. (1989). Sur propositions form undecidable des príncipes matemática et des systèmes apparentés I. Paris: Editeurs du Seuil. 
Hall, C. H., \& Klitgaart, K. (2018). Energy and the Wealth of Nations. Berlin: Springer. https://doi.org/10.1007/978-3-319-66219-0

Hughes, D. (2001). An Environmental History of the World. New York: Routledge.

Lefebvre, H. (2002). Méthodologie des sciences. Paris: Ed. Economica.

Löwy, M. (1987). As aventuras de Karl Marx contra o barão de Munchausen. S. Paul: Editorial Busca Vida.

Marx, K., \& Engels, F. (1968). Cartas sobre as ciências de la naturaliza y las matemáticas. Barcelona: Editorial Anagrama.

Mosley, M., \& Lynch, J. (2010). A History of Science. Rio de Janeiro: Jorge Zahar Ltda.

Oliveira, A. R. E. (2013). The History of the Work Concept: From Physics to Economics. Amsterdam: Springer.

Popper, K. (1959). A Survey of Some Fundamental Problem. The Logic of Scientific Discovery. New York: Routledge Classics.

Popper, K. (1972). Conjectures and Refutations. Brasilia: Publisher of the University of Brasilia. 